\title{
RESEARCH
}

Open Access

\section{Hypoxia with Wharton's jelly mesenchymal stem cell coculture maintains stemness of umbilical cord blood-derived $\mathrm{CD} 34^{+}$cells}

Dewan Zhao', Lingjia Liu', Qiang Chen², Fangfang Wang', Qiuyang Li', Qiang Zeng ${ }^{1}$, Jingcao Huang', Maowen Luo ${ }^{2}$, Wenxian $\mathrm{Li}^{2}$, Yuhuan Zheng ${ }^{1}$ and Ting Liu ${ }^{1 *}$ (D)

\begin{abstract}
Background: The physiological approach suggests that an environment associating mesenchymal stromal cells with low $\mathrm{O}_{2}$ concentration would be most favorable for the maintenance of hematopoietic stem/progenitor cells (HSPCs). To test this hypothesis, we performed a coculture of cord blood CD34 ${ }^{+}$cells with Wharton's jelly mesenchymal stem cells (WJ-MSCs) under different $\mathrm{O}_{2}$ concentration to simulate the growth of HSPCs in vivo, and assessed the impacts on stemness maintenance and proliferation of cord blood HSPCs in vitro.
\end{abstract}

Methods: $\mathrm{CD}_{3} 4^{+}$cells derived from cord blood were isolated and cocultured under $1 \%, 3 \%$, or $20 \% \mathrm{O}_{2}$ concentrations with irradiated WJ-MSCs without adding exogenous cytokines for 7 days. The cultured cells were harvested and analyzed for phenotype and functionality, including total nuclear cells (TNC), CD34 ${ }^{+} \mathrm{Lin}^{-}$cells, colony forming unit (CFU) for committed progenitors, and long-term culture initiating cells (LTC-ICS) for HSPCs. The cytokine levels in the medium were detected with Luminex liquid chips, and the mRNA expression of hypoxia inducible factor (HIF) genes and stem cell signal pathway (Notch, Hedgehog, and Wnt/B-catenin) downstream genes in cord blood HSPCs were confirmed by quantitative real-time polymerase chain reaction ( $\mathrm{QRT} T-\mathrm{PCR}$ ).

Results: Our results showed that the number of TNC cells, CD34 ${ }^{+} \mathrm{Lin}^{-}$cells, and CFU were higher or similar with 20\% $\mathrm{O}_{2}$ (normoxia) in coculture and compared with $1 \% \mathrm{O}_{2}$ (hypoxia). Interestingly, a $1 \% \mathrm{O}_{2}$ concentration ensured better percentages of $\mathrm{CD}_{4}{ }^{+} \mathrm{Lin}^{-}$cells and LTC-IC cells. The hypoxia tension $\left(1 \% \mathrm{O}_{2}\right)$ significantly increased vascular endothelial growth factor (VEGF) secretion and decreased interleukin (IL)-6, IL-7, stem cell factor (SCF), and thrombopoietin (TPO) secretion of WJ-MSCs, and selectively activated the Notch, Wnt/ $\beta$-catenin, and Hedgehog signaling pathway of cord blood HSPCs by HIF-related factors, which may play an important role in stemness preservation and for sustaining HSPC quiescence.

Conclusions: Our data demonstrate that cord blood HSPCs maintain stemness better under hypoxia than normoxia with WJ-MSC coculture, partially due to the increased secretion of VEGF, decreased secretion of IL-6 by WJ-MSCs, and selective activation of stem cell signal pathways in HSPCs. This suggests that the oxygenation may not only be a physiological regulatory factor but also a cell engineering tool in HSPC research, and this may have important translational and clinical implications.

Keywords: Hypoxic coculture, Wharton's jelly mesenchymal stem cells, Ex vivo HSPC expansion

\footnotetext{
* Correspondence: liuting@scu.edu.cn

${ }^{1}$ Department of Hematology, Hematology Research Laboratory, West China

Hospital of Sichuan University, Chengdu, Sichuan, People's Republic of China

Full list of author information is available at the end of the article
}

(c) The Author(s). 2018 Open Access This article is distributed under the terms of the Creative Commons Attribution 4.0 International License (http://creativecommons.org/licenses/by/4.0/), which permits unrestricted use, distribution, and reproduction in any medium, provided you give appropriate credit to the original author(s) and the source, provide a link to the Creative Commons license, and indicate if changes were made. The Creative Commons Public Domain Dedication waiver (http://creativecommons.org/publicdomain/zero/1.0/) applies to the data made available in this article, unless otherwise stated. 


\section{Background}

Umbilical cord blood (UCB) is an alternative source of hematopoietic stem/progenitor cells (HSPCs) for transplantation in malignant and nonmalignant hematologic diseases. However, since the amount of HSPCs in a single unit of cord blood is insufficient for transplantation in most adult patients, the application of cord blood HSPCs remains with a major limitation [1]. The ex-vivo expansion of cord blood HSPCs is one feasible method to increase the HSPC number and has recently become a focus for research. HSPCs maintain their stemness by interacting with stromal cells and the extracellular matrix through cell-to-cell contact and paracrine factor secretion [2]. The microenvironment of the placenta or umbilical cord, where the UCB-HSPCs reside in, is different to that in bone marrow, with the stromal cells including Wharton's jelly mesenchymal stem cells (WJ-MSCs) and vascular endothelial cells being dissimilar to bone marrow stromal cells (e.g., no osteoblasts). Compared with MSCs from the bone marrow, WJ-MSCs not only express cell markers of BM-MSCs, but also additionally express many molecules involved in HSPC expansion and interaction, such as granulocyte colony stimulating factor (G-CSF), granulocyte macrophage colony stimulating factor (GM-CSF), and CD117 [3]. These advantages make WJ-MSCs a preferable feeder layer choice for UCB-HSPC expansion in vitro. Furthermore, in physiological situations, HSPCs are distributed in the tissues with low oxygen tension, and it is now widely accepted that gradients of oxygen from below $1 \%$ in hypoxic niches to $6 \%$ in the sinusoidal cavity exist within the human bone marrow $[4,5]$. Like all other established cell lines, stem cells were typically cultured under ambient oxygen tension with very little attention paid to the metabolic milieu of the niche in which they were grown or normally resided. In this study, we compared the effects of combining WJ-MSCs at different $\mathrm{O}_{2}$ concentrations in coculture on stemness maintenance and proliferation of HSPCs in vitro without adding exogenous cytokines. Our results show that stemness of HPSCs can be better maintained at $1 \% \mathrm{O}_{2}$ with WJ-MSC coculture. Under hypoxia, the levels of secretion of different cytokines via WJ-MSCs and selective activation of stem cell signal pathways may impact a few mechanisms.

\section{Methods}

\section{Isolation and characterization of WJ-MSCs from umbilical cord}

Umbilical cord samples were collected from healthy full-term deliveries after obtaining informed consent as a donation for research. The preparation of the umbilical cord tissue was completed within $12 \mathrm{~h}$. The umbilical cord sample was rinsed with normal saline to remove the residual blood. It was then cut into $1.0-\mathrm{cm}$ long segments, and each segment was cut into a $1.0 \mathrm{~mm}^{3}$ tissue mass and evenly plated in a $10.0-\mathrm{cm}$ dish. The dishes were incubated at $37{ }^{\circ} \mathrm{C}$ under $5 \% \mathrm{CO}_{2}$ for $24 \mathrm{~h}$, and then $10 \mathrm{ml}$ culture medium contained $45 \%$ low-glucose Dulbecco's modified Eagle's medium (DMEM), 45\% Ham's F-12, and 10\% fetal bovine serum (FBS) (Life Technologies, Grand Island, NY, USA) was added. Half of the medium was replaced 7 days later, and then half of the medium was replaced every 3 days until the primary cells reached subconfluence. The primary cells were detached with trypsin-EDTA (0.25\%) (HyClone Laboratories, Logan, Utah, USA) and the reaction was terminated with FBS to passage. Cells harvested from every three dishes were plated in a T-75 flask, and daughter cells were passaged at 1:4 ratios in T-75 flasks. The phenotypic characterization on second- to fourth-passage WJ-MSCs was assayed using a FACScan flow cytometer (Beckman Coulter, USA) for CD90-FITC, CD45-PECY7 (eBioscience, San Diego, CA, USA), CD105-PE, HLA-DR-PECY5, CD34-PE, and CD166-PE (Biolegend, San Diego, CA, USA) according to the manufacturer's instructions. Appropriate isotype controls for nonspecific binding were set for each antibody. For each sample, the assayed cells were analyzed for at least 10,000 events. The WJ-MSCs expressed CD90, CD105, and CD166, and were negative for CD45, CD34, and HLA-DR (Fig. 1).

\section{Isolation and purification of $\mathrm{CD}_{3} 4^{+}$cells from umbilical cord blood}

Umbilical cord blood was collected from normal full-term delivery after obtaining informed consent from the mothers as a donation for banking, and only cord blood samples not appropriate for banking $(<100 \mathrm{ml})$ were used in our experiments. We mixed cord blood with $6 \%$ hetastarch in $0.9 \%$ sodium chloride (Hospira, USA) at a ratio of 4:1 and let it stand for approximately 30 min to allow most of the red cells to form a sediment. Cells in the supernatant was laid onto Ficoll-Paque PLUS (GE Healthcare Bio-Sciences, Pittsburgh, USA) and centrifuged to collect mononuclear cells (MNCs) by depleting the platelets, plasma, and residual red cells. Enrichment of CD34 ${ }^{+}$cells was performed with two runs of immunomagnetic selection on MiniMACS columns (Miltenyi Biotec, Gladbach, Germany) in accordance with the manufacturer's instructions.

\section{Coculture of WJ-MSCs and CD34 ${ }^{+}$cells under hypoxic or normoxic conditions}

WJ-MSCs at passages 2 to 4 were harvested and radiated (25 Gy) to prevent overgrowth. We then plated them into 12 -well plates $\left(8 \times 10^{4} /\right.$ well $)$ with $\mathrm{H} 5100$ medium contained $10^{-6} \mathrm{M}$ hydrocortisone (StemCell Technologies, Vancouver, BC, Canada). At least $24 \mathrm{~h}$ later, we removed the medium and seeded purified CD34 ${ }^{+}$cells (suspended 

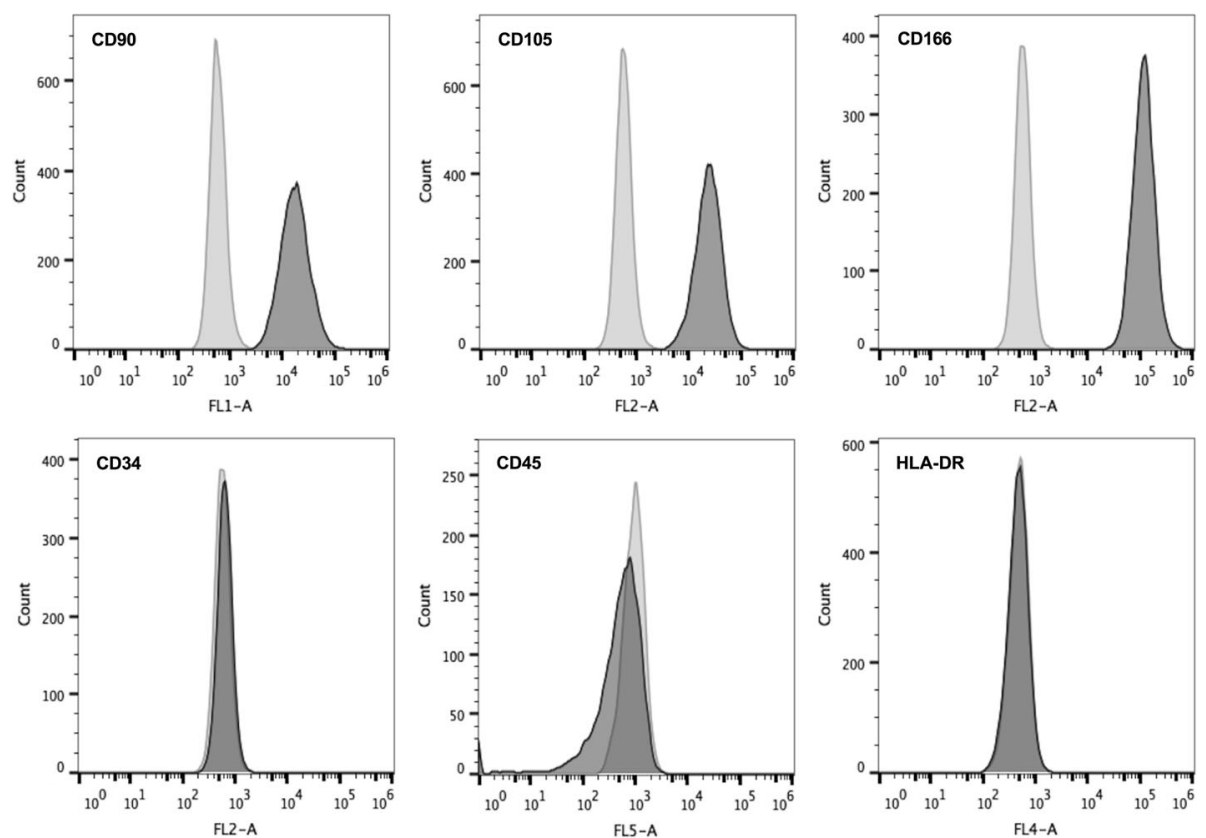

Fig. 1 The characterization of WJ-MSCs. Wharton's jelly mesenchymal stem cells (MSCS) were positive for CD90, CD105, and CD166, and negative for CD34, CD45, and HLA-DR. The light gray histograms show the isotype control-stained cells and the dark gray histograms show the antibody-stained cells. The control population was stained with matched isotype antibodies

in $\mathrm{H} 5100$ medium with $10^{-6} \mathrm{M}$ hydrocortisone) into the plate $\left(4 \times 10^{4} /\right.$ well $)$. WJ-MSCs and $\mathrm{CD}^{+} 4^{+}$cells were cocultured at $37{ }^{\circ} \mathrm{C}$ and $5 \% \mathrm{CO}_{2}$ under normoxic $\left(20 \% \mathrm{O}_{2}\right)$ and hypoxic $\left(3 \%\right.$ and $\left.1 \% \mathrm{O}_{2}\right)$ conditions for 7 days without adding exogenous cytokines, replacing half of the medium every 3 days. Hypoxic cultures were made in a two-gas incubator (Thermo Scientific, Forma ${ }^{\text {ax }}$ Steri-Cycle i160 STERI-cycle, USA) equipped with an $\mathrm{O}_{2}$ probe to regulate $\mathrm{N}_{2}$ levels. We also set a control group without WJ-MSCs as feeder layers, with the medium and culture conditions as described above.

\section{Flow cytometry analysis}

We defined the $\mathrm{CD} 34^{+}, \mathrm{CD}_{10}^{-}, \mathrm{CD} 14^{-}$, and $\mathrm{CD} 19^{-}$cells as $\mathrm{CD} 34^{+}$Linage $^{-}\left(\mathrm{CD} 34^{+} \mathrm{Lin}^{-}\right)$cells, which represent cord blood HSPCs. At day 7, we collected the supernatant and detached the adherent cells containing WJ-MSCs and HSPCs (attached to the WJ-MSCs). Viable total nucleated cells (TNC) were counted via the Trypan Blue staining method. Flow cytometry staining was performed with CD34-PECY7, CD45-FITC (eBioscience, San Diego, CA, USA), CD10-APC, CD14-APC/Cy7, and CD19-PE (Biolegend, San Diego, CA, USA) antibodies, and then samples were analyzed using a FACScan flow cytometer (Beckman Coulter, USA). For each sample, at least 30,000 events were recorded. The isotype antibodies were used to determine the level of nonspecific binding.

\section{Colony-forming cell assay}

On day 7, the harvested cells from each group were plated in semisolid culture (H4434, Stem Cell Technologies, Vancouver, BC, Canada) following the manufacturer's instructions for the colony-forming unit (CFU) assay. After incubation at $37{ }^{\circ} \mathrm{C}$ under $5 \% \mathrm{CO}_{2}$ at $100 \%$ humidity for 14 days, the total colony-forming unit (T-CFU), burst-forming unit-erythroid (BFU-E), and colony-forming unit-granulocyte/macrophage (CFU-GM) levels were scored under an inverted microscope. Each $\mathrm{CFU}$ is equivalent to a colony-forming cell (CFC).

\section{Long-term culture-initiating cell assay}

M2-10B4 (ATCC), a murine fibroblast cell line, was used as a feeder layer. At least $24 \mathrm{~h}$ before assay, M2-10B4 cells were radiated ( $80 \mathrm{~Gy})$ and plated in six-well plates $(2.5 \times$ $10^{5} /$ well). The plates were coated with collagen solution (StemCell Technologies, Vancouver, BC, Canada). Cells harvested from coculture systems at different oxygen concentrations on day 7 were resuspended with $\mathrm{H} 5100$ containing $10^{-6} \mathrm{M}$ hydrocortisone (StemCell Technologies, Vancouver, BC, Canada) and then seeded into the plate $\left(2 \times 10^{5} /\right.$ well $)$ with the feeder layers. At weekly intervals we replaced half of the medium. Both nonadherent and adherent cells were harvested at week 5 and plated in semisolid culture (H4434, StemCell Technologies, Vancouver, BC, Canada) for CFC assay. After 18 days, colonies were scored under an inverted microscope. The 
long-term culture-initiating cell (LTC-IC) number was calculated according to the manufacturer's instructions.

\section{Cytokine concentration analysis}

WJ-MSCs were radiated (25 Gy) and plated into 12-well plates $\left(8 \times 10^{4} /\right.$ well $)$ suspended with H5100 medium containing $10^{-6} \mathrm{M}$ hydrocortisone (StemCell Technologies, Vancouver, BC, Canada). Twenty-four hours later, we replaced the medium and cultured the WJ-MSCs at $20 \% \mathrm{O}_{2}$ or $1 \% \mathrm{O}_{2}$, replacing half of the medium twice a week. On day 7 , we collected the supernatant of the medium and analyzed the concentration of the following cytokines in each group by Luminex assays Kit (R\&D Systems, USA) on Luminex 200: tumor necrosis factor (TNF)-alpha, interleukin (IL)-6, IL-3, vascular endothelial growth factor (VEGF), stem cell factor (SCF), IL-7, GM-CSF, macrophage colony stimulating factor (M-CSF), G-CSF, and thrombopoietin (TPO). H5100 culture medium with $10^{-6} \mathrm{M}$ hydrocortisone incubated under the same conditions for each group was set as a blank control.

\section{Signal pathway assays in MSC-HSPC low $\mathrm{O}_{2}$ cocultures}

We harvested the nonadherent cells of each coculture system on day 7. Total RNA was isolated using the MicroElute Total RNA Kit (OMEGA Bio-tek, Norcross, Georgia). Single-strand cDNA was synthesized using the HiFiScript cDNA Synthesis Kit (CW-Bio, Jiangsu, China). Quantitative real-time polymerase chain reaction (qRT-PCR) was performed using the SYBR Green PCR Master Mix (Fermentas, Vilnius, Lithuania) on a CFX96 Touch $^{\text {Tu }}$ Real-Time PCR Detection System (Bio-Rad).
The housekeeping gene $\beta$-actin was used as a reference gene. Detected genes included: the hypoxia inducible genes HIF1- $\alpha$, HIF2- $\alpha$, and ARNT; the Notch pathway downstream genes HES1, HES3, HEY1, and HEY2; the Wnt/ $\beta$-catenin downstream genes AXIN2, MMP7, and TCF-1; and the Hedgehog downstream genes GLI1, PTCH1, PTCH2, and SMO. Gene-specific primer sets are listed in Table 1.

\section{Statistical analysis}

The statistical differences between each group were analyzed using the SPSS 20.0 statistical software for all the experiment data. The comparison was analyzed between two groups with an independent sample $t$ test, and among three groups with single-factor analysis of variance (ANOVA). The values were plotted as mean \pm standard deviation. Probability values $P<0.05$ were considered statistically significant.

\section{Results}

The influence of different oxygen concentrations on cord blood HSPC coculture

In this study, we defined $\mathrm{CD} 34^{+} \mathrm{CD} 10^{-} \mathrm{CD} 14^{-} \mathrm{CD} 19^{-}$ phenotypic cells as the CD34 $4^{+}$lin $^{-}$HSPC cells (Fig. 2). First, we compared the effects of $3 \% \mathrm{O}_{2}$ with $20 \% \mathrm{O}_{2}$ on the WJ-MSC-HSPC coculture in vitro for 7 days. The results showed that there was no significant difference between these two groups in the percentage or cell numbers of CD34 ${ }^{+} \mathrm{Lin}^{-}$cells, as well as the number of TNC $(P>0.05)$. We then cocultured UCB-HSPCs with WJ-MSCs at $1 \% \mathrm{O}_{2}$ and $20 \% \mathrm{O}_{2}$ concentrations. We

Table 1 Quantitative real-time polymerase chain reaction primer list

\begin{tabular}{|c|c|c|c|}
\hline Function & Gene & Forward primer & Reverse primer \\
\hline \multirow[t]{3}{*}{ Hypoxia inducible } & HIF1A & GGTCTAGGAAACTCAAAACCTGA & TCCTCACACGCAAATAGCTGA \\
\hline & HIF2A & ATCAGCTTCCTGCGAACACA & GCTCCACCTGTGTAAGTCCC \\
\hline & ARNT & ACTACTGCCAACCCCGAAAT & CTCTGGACAATGGCTCCTCC \\
\hline \multirow[t]{4}{*}{ Notch pathway } & HES1 & GTGTCAACACGACACCGGAT & GGAATGCCGCGAGCTATCTT \\
\hline & HES3 & GATTTCCAAGCCGCTGATGG & TTCCGGATCTGGTGCGAGTA \\
\hline & HEY1 & TGCGGATTGAGCTAGTGCAT & AAGTAACCTTGGTCTCCCGT \\
\hline & HEY2 & GTGGGAAAGAGCCGCTAGG & GAGCTAGTACTITGCCCCGA \\
\hline \multirow[t]{3}{*}{ Wnt/ßcatenin pathway } & AXIN2 & GCAACTCAGTAACAGCCCGA & СтCСTCTCTITTACAGCAGGGC \\
\hline & MMP7 & GTCTCTGGACGGCAGCTATG & GATAGTCCTGAGCCTGTTCCC \\
\hline & TCF-1 & CCAAGAATCCACCACAGAGACA & CAATGCCTATGGCTTCCTTGC \\
\hline \multirow[t]{4}{*}{ Hedgehog pathway } & GLI1 & AGCCTTCAGCAATGCCAGTGAC & GTCAGGACCATGCACTGTCTTG \\
\hline & PTCH1 & GCTGCACTACTTCAGAGACTGG & CACCAGGAGTTTGTAGGCAAGG \\
\hline & PTCH2 & GCACTATTACCGCAACTGGCTAC & TCTCCAGTCTGGATGAGCAGCT \\
\hline & $\mathrm{SMO}$ & AATGCGTGCTTCTITGTGGG & TCTCATTGGAGGTGGGCTCC \\
\hline House keeping & $\beta$-actin & AGAGCTACGAGCTGCCTGAC & AGCACTGTGTTGGCGTACAG \\
\hline
\end{tabular}




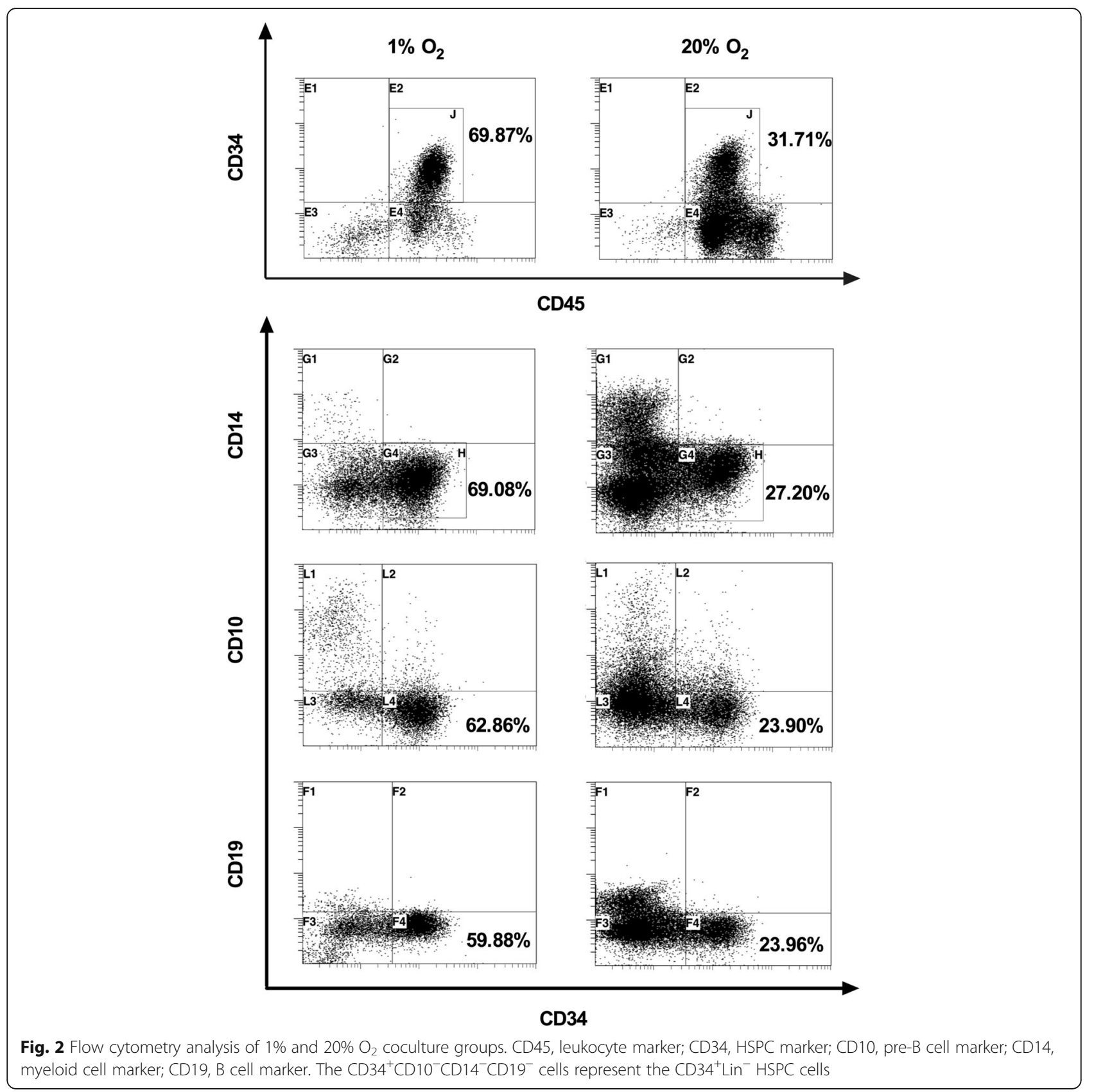

collected cells on day 7 , and the TNC counts at $1 \% \mathrm{O}_{2}$ and $20 \% \mathrm{O}_{2}$ were $3.68 \pm 1.97 \times 10^{4}$ and $13.50 \pm 5.04 \times 10^{4}$ $(P<0.05)$, respectively; the number of $\mathrm{CD}^{2} 4^{+} \mathrm{Lin}^{-}$cells was $2.70 \pm 1.07 \times 10^{4}$ and $3.82 \pm 1.28 \times 10^{4}(P>0.05)$, respectively; and the percentage of $\mathrm{CD} 34^{+} \mathrm{Lin}^{-}$cells was $76.83 \pm 10.56 \%$ and $29.05 \pm 7.74 \%(P<0.01)$, respectively. As a control, compared with the coculture group under $1 \% \mathrm{O}_{2}$ conditions, the number of TNC and $\mathrm{CD} 34^{+} \mathrm{Lin}^{-}$ cell in the suspension culture group was $1.06 \pm 0.10 \times$ $10^{4}$ and $0.57 \pm 0.06 \times 10^{4}$, respectively, and the percentage of CD34 ${ }^{+} \mathrm{Lin}^{-}$was $53.87 \pm 5.02 \%(P<0.05)$ (Fig. 3).

\section{Differentiation and long-term reconstruction capacity} maintenance

The TNCs were harvested on day 7 from the $1 \% \mathrm{O}_{2}$ and $20 \% \mathrm{O}_{2}$ culture systems for CFU and LTC-IC assay. Methylcellulose colony-forming assay was performed to evaluate the differentiation potential (CFU), and the LTC-IC was evaluated for the maintenance capacity of HSPCs in vitro (Fig. 4). Among the TNCs harvested per well, the $1 \% \mathrm{O}_{2}$ group induced $38,542 \pm$ 24,647 T-CFUs and 31,846 $\pm 20,165$ CFU-GMs, and the $20 \% \mathrm{O}_{2}$ group induced $80,331 \pm 6079 \mathrm{~T}$-CFUs and 

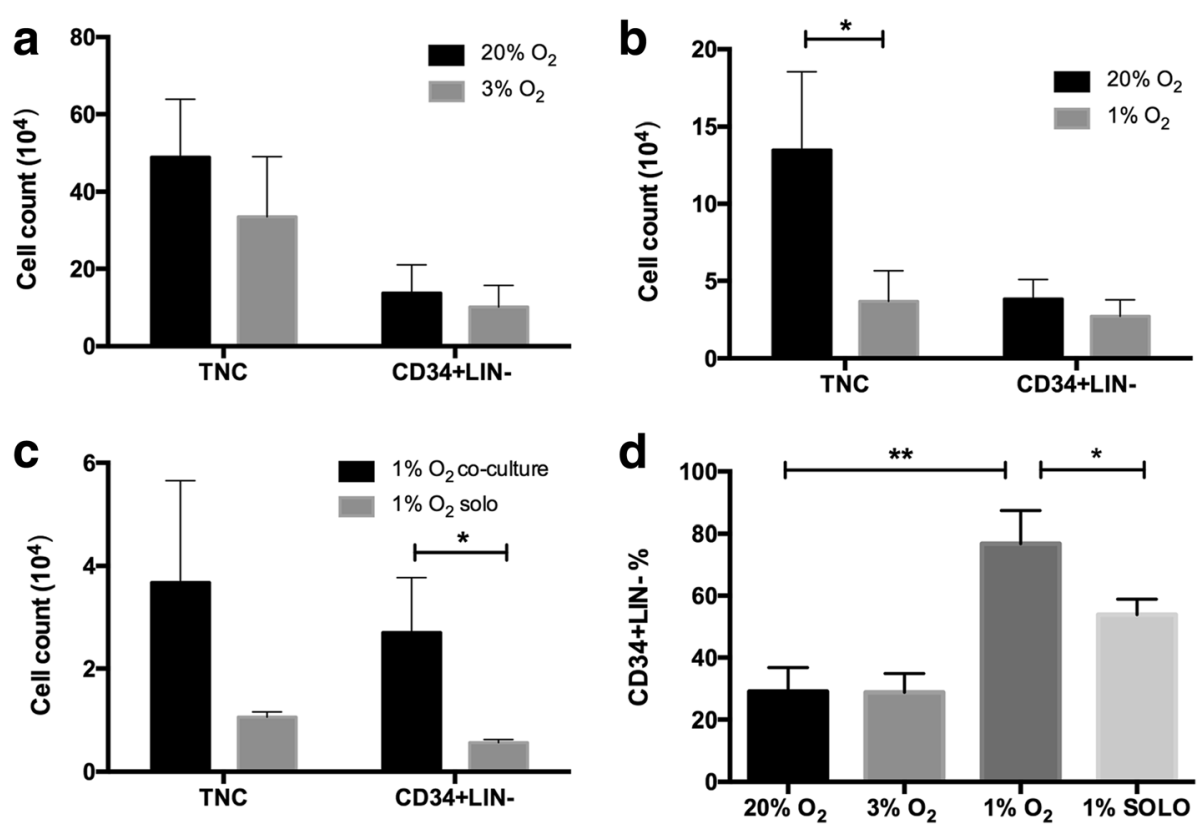

Fig. 3 The influence of different oxygen concentration on the ex-vivo culture of cord blood HSPCs $(n=4)$ ) a The total nucleated cells (TNCs) and $\mathrm{CD}_{4}{ }^{+} \mathrm{Lin}^{-}$cell numbers in $3 \%$ and $20 \% \mathrm{O}_{2}$ groups on day 7 . $\mathbf{b}$ The TNCs and $\mathrm{CD}_{3} 4^{+} \mathrm{Lin}^{-}$cell number in $1 \%$ and $20 \% \mathrm{O}_{2}$ groups. c The TNCs and $\mathrm{CD}_{3}{ }^{+} \mathrm{Lin}^{-}$cell number in coculture and suspended culture group (solo) at $1 \% \mathrm{O}_{2}$. $\mathbf{d}$ The percentage of $\mathrm{CD}_{3} 4^{+} \mathrm{Lin}^{-}$cells in the different groups. ${ }^{*} P<0.05,{ }^{* *} P<0.01$

$59,013 \pm 6283$ CFU-GMs $(P>0.05)$. The BFU-E results for the $1 \% \mathrm{O}_{2}$ and $20 \% \mathrm{O}_{2}$ group were $6697 \pm 4548$ and $21,317 \pm 2424(P<0.05)$ (Fig. 4a). The number of LTC-IC from the $1 \% \mathrm{O}_{2}$ and $20 \% \mathrm{O}_{2}$ groups were $298 \pm 45$ and $244 \pm 89$, respectively $(P>0.05)$. In each
10,000 TNCs, the LTC-IC amounts for the $1 \% \mathrm{O}_{2}$ and $20 \% \mathrm{O}_{2}$ groups were $126 \pm 37$ and $12 \pm 4$, respectively, which indicated that hypoxia culture could maintain LTC-IC count capacity better than normoxia culture $(P<0.05)$.

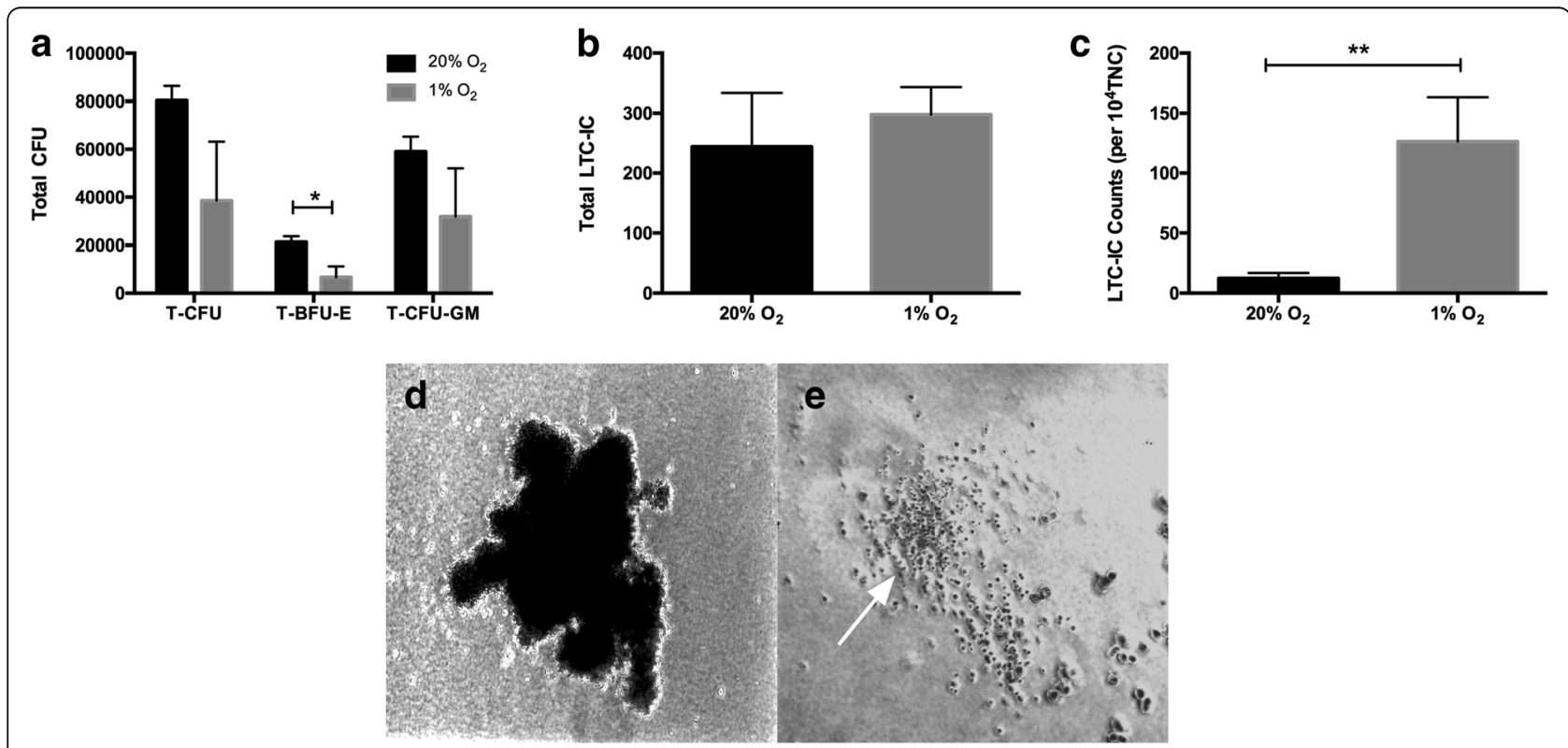

Fig. 4 The differentiation potential and long-term reconstruction capacity maintenance of $\operatorname{HSPCS}(n=4)$. a The total colony-forming unit (T-CFU), total burst-forming unit-erythroid (T-BFU-E), and total colony-forming unit-granulocyte/macrophage (T-CFU-GM) number per well in 20\% and $1 \%$ $\mathrm{O}_{2}$ groups. b The long-term culture-initiating cell (LTC-IC) amount per well in $20 \%$ and $1 \% \mathrm{O}_{2}$ groups. c The LTC-IC amount per 10,000 total nucleated cells (TNC) in $20 \%$ and $1 \% \mathrm{O}_{2}$ groups. d An image of BFU-E. e An image of CFU-GM (white arrow). ${ }^{*} P<0.05$, ${ }^{* *} P<0.01$ 


\section{Concentration of cytokines secreted by WJ-MSCs}

To explore the cytokine levels secreted by WJ-MSCs at different oxygen concentration, WJ-MSCs were cultured for 7 days under conditions of $1 \% \mathrm{O}_{2}$ and $20 \% \mathrm{O}_{2}$ and the medium was collected and the cytokines measured by Luminex liquid-phase chip. We assayed 10 cytokines related to hematopoiesis: TNF-alpha, IL-6, IL-3, VEGF, SCF, IL-7, GM-CSF, M-CSF, G-CSF, and TPO. The results show that the culture medium contained much higher levels of VEGF in the $1 \% \mathrm{O}_{2}$ group than the $20 \%$ $\mathrm{O}_{2}$ group $(P<0.01)$, and more IL-6, IL-7, SCF, and TPO in the $20 \% \mathrm{O}_{2}$ group than in the $1 \% \mathrm{O}_{2}$ group $(P<0.05)$ (Table 2 and Fig. 5).

\section{Stem cell pathway activation under hypoxia}

To investigate whether stem cell pathways were activated under hypoxic conditions, we analyzed the mRNA expression levels of the suspended cells for three important stem cell activation pathways (Notch, Wnt $/ \beta$-catenin, and Hedgehog) downstream genes and hypoxia inducible genes (HIF1, HIF2, and ARNT). Higher mRNA expressions were observed in HIF1, HIF2, and ARNT genes in the $1 \% \mathrm{O}_{2}$ group than in the $20 \% \mathrm{O}_{2}$ group (Fig. 6). Furthermore, some downstream gene expression upregulation was seen: HES1 on the Notch pathway; MMP7 on the Wnt/ $\beta$-catenin downstream; and PTCH1 and SMO on the Hedgehog pathway $(P<0.05)$ (Fig. 6). However, for other genes such as HES3, HES5, HEY1, HEY2, TCF-1, Gli1, and PTCH2 after qRT-PCR 50 cycles, the fluorescence amplification curves of cDNA did not reach the plateau stage. This indicates that these genes were not activated in the hematopoietic cells in our low $\mathrm{O}_{2}$ coculture system.

Table 2 The cytokine levels at different $\mathrm{O}_{2}$ tension $(n=4)$

\begin{tabular}{lll}
\hline $\mathrm{pg} / \mathrm{ml}$ & $20 \% \mathrm{O}_{2}$ & $1 \% \mathrm{O}_{2}$ \\
\hline TNF-a & $7.18 \pm 2.82$ & $3.65 \pm 0.17$ \\
IL6 & $4789.67 \pm 1642.70^{*}$ & $792.67 \pm 615.10$ \\
IL3 & $56.62 \pm 9.92$ & $42.42 \pm 4.95$ \\
VEGF & $7.83 \pm 5.29^{* *}$ & $584.83 \pm 77.11$ \\
SCF & $15.82 \pm 3.52^{*}$ & $9.08 \pm 0.62$ \\
IL7 & $4.93 \pm 1.34^{*}$ & $1.97 \pm 0.10$ \\
GM-CSF & $38.47 \pm 38.23$ & $45.65 \pm 49.07$ \\
M-CSF & $1056.17 \pm 669.73$ & $143.00 \pm 28.99$ \\
G-CSF & $33,893.83 \pm 28,728.97$ & $7725.50 \pm 3391.86$ \\
TPO & $205.50 \pm 52.79^{*}$ & $113.83 \pm 5.58$
\end{tabular}

G-CSF granulocyte colony stimulating factor, GM-CSF granulocyte macrophage colony stimulating factor, IL interleukin, $M$-CSF macrophage colony stimulating factor, SCF stem cell factor, TNF Tumor necrosis factor, TPO thrombopoietin, VEGF vascular endothelial growth factor ${ }^{*} P<0.05,{ }^{*} P<0.01$, versus $1 \% \mathrm{O}_{2}$

\section{Discussion}

The physiological approach suggests that a microenvironment associating MSCs with a low $\mathrm{O}_{2}$ concentration would be most favorable for the maintenance of HSPCs in the course of ex-vivo expansion. The microenvironment of UCB-HSPCs in placenta or the umbilical cord is different from that in the bone marrow, and the stromal cells are dissimilar to those in bone marrow being composed of other stromal cells including WJ-MSCs and vascular endothelial cells. The microenvironment of bone marrow or cord blood is extremely hypoxic compared with ambient air [6]. The physiological low $\mathrm{O}_{2}$ concentrations protect the primitive hematopoietic cells against oxidative stress in vivo. Although some studies suggest that $3 \% \mathrm{O}_{2}$ culture conditions could maintain the stemness of UCB-HSPCs better than $20 \% \mathrm{O}_{2}[7,8]$, our study showed some different results which might be due to our coculture system using WJ-MSCs as feeder layers and without the addition of exogenous cytokines. Furthermore, we compared a lower oxygen concentration (1\%) with $20 \% \mathrm{O}_{2}$; the results showed that, although the number of $\mathrm{CD}_{34}{ }^{+} \mathrm{Lin}^{-}$cells was lower at $1 \% \mathrm{O}_{2}$ than at $20 \%$ $\mathrm{O}_{2}$, the percentage of $\mathrm{CD} 34^{+} \mathrm{Lin}^{-}$cells was significant higher at $1 \% \mathrm{O}_{2}$. Similar trends were also observed for T-CFU, CFU-GM, BFU-E, and LTC-IC in the $1 \% \mathrm{O}_{2}$ and $20 \% \mathrm{O}_{2}$ groups, and the LTC-IC number per 10,000 TNCs in the $1 \% \mathrm{O}_{2}$ group was significant higher than the $20 \%$ $\mathrm{O}_{2}$ group, indicating that a hypoxia culture could preserve the functional capacity to maintain LTC-IC counts better than a normoxia culture. Eliasson et al. cultured mouse bone marrow HSPCs at $1 \% \mathrm{O}_{2}$ and $20 \% \mathrm{O}_{2}$ in suspension and found that a $1 \% \mathrm{O}_{2}$ culture system could better maintain the stemness of HSPCs [9]. These results confirmed the major role of the microenvironment for stromal cells and low $\mathrm{O}_{2}$ concentrations for stem cell maintenance.

The mechanisms of how low $\mathrm{O}_{2}$ can maintain the stemness of HSPCs is still obscure. Some publications have already evaluated the effects of hypoxia on UCB-HSPCs. The reduction in cell division kinetics and a higher percentage of $\mathrm{G}_{0}$ cells in hypoxic $\mathrm{O}_{2}$ compared with $20 \% \mathrm{O}_{2}$ conditions have been reported $[6,10]$. Low $\mathrm{O}_{2}$ tension increases the expression of hypoxia-inducible factor (HIF)-1 which mediates an active switch from oxidative to glycolytic metabolism, limiting reactive oxygen species (ROS) production and promoting its degradation. ROS terminates the quiescent state of HSPCs and promotes their differentiation [11]. Recently, Mantel et al. reported that, in ambient air, HSPCs were compromised through the activation of the mitochondrial permeability transition pore; this process can be inhibited by setting a hypoxia condition during harvesting and transplantation of donor bone marrow or by using cyclosporin A, which can protect HSPCs from extraphysiologic oxygen shock/stress (EPHOSS) [12]. 

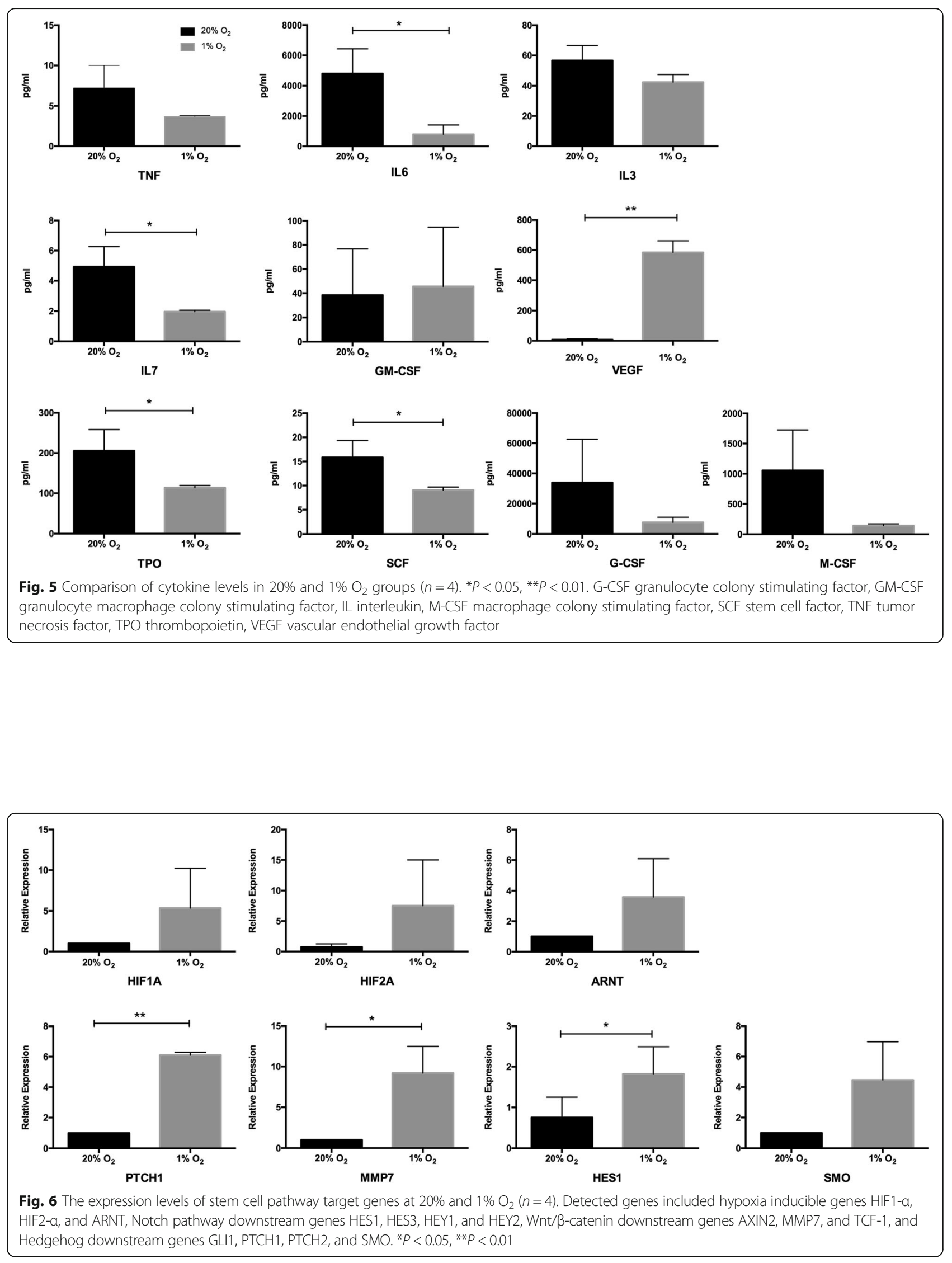
The mechanisms behind MSC hematopoiesis support are still elusive, whether cell-to-cell direct contact and/ or soluble factor secretion $[13,14]$. Proteomic analysis of the WJ-MSCs revealed high levels of interleukins (IL-1a, IL-6, IL-7, IL-8), as well as SCF, hepatocyte growth factor (HGF), and ICAM-1, suggesting once again that they may be the agents involved in the expansion of UCB-HPSCs [15]. To investigate the combination roles of WJ-MSCs with low $\mathrm{O}_{2}$, we assayed 10 cytokines involved in hematopoiesis: TNF-alpha, IL-6, IL-3, VEGF, SCF, IL-7, GM-CSF, M-CSF, G-CSF, and TPO in the supernatant of WJ-MSC coculture medium at $1 \%$ and $20 \% \mathrm{O}_{2}$. The results show that the culture medium contained much higher VEGF levels in the $1 \% \mathrm{O}_{2}$ group, and higher levels of IL-6, IL-7, SCF, and TPO in the $20 \%$ $\mathrm{O}_{2}$ group. It is surprising that VEGF level was so high in our coculture system at $1 \% \mathrm{O}_{2}$, and this indicates that the hypoxic response of WJ-MSCs is characterized by a rapid increase in VEGF secretion and glycolytic activity. This rapid increase in VEGF secretion may play a critical role in the survival and expansion of human UCB-HPSCs under hypoxia. VEGF is a principal regulator of hematopoiesis, which provides for quiescence and self-renewal as well as restraining the differentiation of HSPCs $[16,17]$. This may explain the reason why the TNCs harvested at $1 \% \mathrm{O}_{2}$ contained more long-term reconstruction cells and less lineage-committed progenitor cells. The function of IL-6 and IL-7 is to induce the differentiation of HSPCs [18, 19], and our results showed that the levels of IL- 6 and IL-7 were significantly higher at $20 \% \mathrm{O}_{2}$. This may indicate a differentiation role under normoxia stimulation. Other cytokines, such as TNF- $\alpha$, IL-3, M-CSF, and G-CSF which promote differentiation $[20,21]$, tended to decrease at $1 \% \mathrm{O}_{2}$. This may contribute to maintaining the stemness of HSPCs. In a recent research, Paquet et al. cultured human bone marrow MSCs at different oxygen concentration (21\%, 5\%, and $0.1 \%)$, and showed that hypoxic conditions increased the MSC paracrine secretion of angiogenic mediators such as VEGF, IL-8, RANTES, and monocyte chemoattractant protein 1, and significantly decreased the expression of several inflammatory/immunomodulatory mediators, such as IL-6, IL-15, and IL-1Rap [22]. Majumdar et al. compared the effects of normoxia $\left(20 \% \mathrm{O}_{2}\right)$ with hypoxia $\left(2 \% \mathrm{O}_{2}\right)$ on the paracrine secretion of WJ-MSCs; their results showed there was significantly increased secretion of VEGF and HGF under hypoxia [23]. These studies are consistent with our findings. Taken together, MSCs exposed to a hypoxic culture increase the expression of VEGF, promote the phosphorylation of focal adhesion kinase [24], and increase the expression of chemokine receptors such as CXCR4 and CX3CR1 [25].
To investigate whether stem cell pathways were activated under hypoxic condition, we analyzed the mRNA expression levels of the harvested HSPCs on hypoxia-related genes (HIF1, HIF2, and ARNT) and Notch, Wnt/ $\beta$-catenin, and Hedgehog pathway downstream genes. Our findings showed that $1 \% \mathrm{O}_{2}$ induced higher mRNA expressions of HIF1, HIF2, and ARNT genes, and upregulated some downstream gene expression, such as HES1 on the Notch pathway, MMP7 on the Wnt/ $\beta$-catenin downstream, and PTCH1 and SMO on the Hedgehog pathway. Hypoxic tension promotes the expression of the hypoxia inducible factor-related genes HIF- $1 \alpha$, HIF- $2 \alpha$, and ARNT. These genes encode HIF- $\alpha$ subunits that are stabilized under low oxygen tensions and exhibit tissue-restricted expression. Upon stabilization, these subunits dimerize with the $\beta$-subunit, HIF- $\beta$ (ARNT), and translocate to the nucleus to regulate a spectrum of genes to maintain oxygen homeostasis, glucose metabolism, angiogenesis, erythropoiesis, and iron metabolism [26]. Hypoxia has been shown to activate molecular pathways in multiple stem cell systems. Notch signaling is widely appreciated to be critical for the maintenance of undifferentiated stem and progenitor cell populations. Ezashi et al. found that oxygen tensions as low as $1 \%$ appeared to decrease proliferation and maintain pluripotency of stem cells, while higher oxygen tensions (3-5\%) appeared to maintain pluripotency with no effect on proliferation [27]. Our experiments showed that the activation of the three important signal pathways in HSPCs under hypoxia was significantly enhanced. However, the downstream genes of the three pathways were selectively activated and, thus far, their functions are not able to be shown. Some researchers have tried to confirm a correlation between HIF-related genes and stem cell pathways under hypoxia. Mukherjee et al. reported that, in drosophila blood cells, HIF- $\alpha$ binds to the Notch ligand intracellular segment to promote Notch downstream gene expression [28]. Bijlsma et al. found that HIF1- $\alpha$ induced hedgehog pathways activated by PTCH1 in the mouse [29]. Mazumdar et al. verified the relationship between HIF1 and TCF-1 in mouse embryonic stem cells [30], and Liu et al. confirmed the relationship between HIF1- $\alpha$ and MMP7 protein content in gastric cancer cell lines [31]. The increased expression of HIF-related factors, HES1, PTCH1, and MMP7 under hypoxia in our study can partially explain the positive effect of a hypoxic coculture system on stemness maintenance of UCB-HSPCs, but how the stem cell pathways are activated remains to be further explored.

\section{Conclusions}

In this study, we used WJ-MSCs as a feeder layer under low $\mathrm{O}_{2}$ tension to simulate the physiological microenvironment in which UCB-HSPCs reside to explore the effects of the coculture system on stemness maintenance and proliferation of HSPCs in vitro without adding 
exogenous cytokines. The results showed that the populations of $\mathrm{CD}_{34}{ }^{+} \mathrm{Lin}^{-}$cells and LTC-ICs could be preserved better at $1 \% \mathrm{O}_{2}$ than at $20 \% \mathrm{O}_{2}$. Hypoxia increased VEGF secretion and decreased IL-6 secretion and selectively activated the Notch/Wnt/Hedgehog signaling pathway in UCB-HSPCs via HIF-related factors, which plays an important role in preserving stemness and sustaining HSPC quiescence. However, our findings are only a starting point for pursuing optimizing protocols aimed at expanding UCB-HSPCs ex vivo, such as adding some key cytokines and growth factors, using optimal low $\mathrm{O}_{2}$ tension to protect HSPCs from EPHOSS to preserve the capacity of stemness of HSPCs, and developing bioreactor systems for in-vitro cultures, which may have important translational and clinical implications.

\begin{abstract}
Abbreviations
BFU-E: Burst-forming unit-erythroid; CFC: Colony-forming cell; CFU: Colonyforming unit; CFU-GM: Colony-forming unit-granulocyte/macrophage; EPHOSS: Extraphysiologic oxygen shock/stress; G-CSF: Granulocyte colony stimulating factor; GM-CSF: Granulocyte macrophage colony stimulating factor; HGF: Hepatocyte growth factor; HIF: Hypoxia inducible factor; HSPC: Hematopoietic stem/progenitor cell; IL: Interleukin; LTC-IC: Longterm culture-initiating cell; M-CSF: Macrophage colony stimulating factor: MNC: Mononuclear cell; qRT-PCR: Quantitative real-time polymerase chain reaction; ROS: Reactive oxygen species; SCF: Stem cell factor; T-CFU: Total colony-forming unit; TNC: Total nucleated cell; TNF: Tumor necrosis factor; TPO: Thrombopoietin; UCB: Umbilical cord blood; VEGF: Vascular endothelial growth factor; WJ-MSC: Wharton's jelly mesenchymal stem cell
\end{abstract}

\section{Acknowledgments}

The authors would like to thank all of the mothers who donated the umbilical cord and cord blood samples for cord blood stem cell banking and for this study. This work was supported by a grant from National Natural Science Foundation of People's Republic of China (no. 81370595).

\section{Funding}

This work was supported by a grant from the National Natural Science Foundation of People's Republic of China (no. 81370595).

\section{Availability of data and materials}

Please contact author for data requests.

\section{Authors' contributions}

DZ and TL conceived and designed the study. DZ, LL, FW, QL, and QZ performed the experiments. QC, ML, WL, JH, and $Y Z$ contributed reagents/ materials/analysis tools. DZ and TL analyzed the data and wrote the paper. All authors read and approved the final manuscript.

\section{Ethics approval and consent to participate}

According to the Declaration of Helsinki, umbilical cord and cord blood samples were collected in local hospitals from healthy full-term deliveries after obtaining informed consent for a donation for cord blood stem cell banking with the compliance of the ethical committee review board of Sichuan Cord Blood Stem Cell Bank (LL-20100310-QX-1; LL-20151029-QD-1). The ethical committee of West China Hospital of Sichuan University approved consenting procedures for the laboratory studies.

\section{Competing interests}

The authors declare that they have no competing interests.

\section{Publisher's Note}

Springer Nature remains neutral with regard to jurisdictional claims in published maps and institutional affiliations.

\section{Author details}

'Department of Hematology, Hematology Research Laboratory, West China Hospital of Sichuan University, Chengdu, Sichuan, People's Republic of China. ${ }^{2}$ Sichuan Cord Blood Stem Cell Bank, Chengdu, Sichuan, People's Republic of China.

Received: 9 March 2018 Revised: 30 April 2018

Accepted: 13 May 2018 Published online: 13 June 2018

\section{References}

1. Rocha V, Gluckman E. Eurocord-Netcord registry and European Blood and Marrow Transplant group. Improving outcomes of cord blood transplantation: HLA matching, cell dose and other graft- and transplantation-related factors. Br J Haematol 2009;147(2):262-274.

2. Morrison SJ, Scadden DT. The bone marrow niche for haematopoietic stem cells. Nature. 2014;505(7483):327-34.

3. Lo lacono M, Anzalone R, La Rocca G, Baiamonte E, Maggio A, Acuto S. Wharton's jelly mesenchymal stromal cells as a feeder layer for the ex vivo expansion of hematopoietic stem and progenitor cells: a review. Stem Cell Rev. 2017;13(1):35-49.

4. Mohyeldin A, Garzon-Muvdi T, Quinones-Hinojosa A. Oxygen in stem cell biology: a critical component of the stem cell niche. Cell Stem Cell. 2010;7(2):150-61.

5. Eliasson P, Jonsson Jl. The hematopoietic stem cell niche: low in oxygen but a nice place to be. J Cell Physiol. 2010;222(1):17-22.

6. Guitart AV, Hammoud M, Dello Sbarba P, Ivanovic Z, Praloran V. Slowcycling/quiescence balance of hematopoietic stem cells is related to physiological gradient of oxygen. Exp Hematol. 2010;38(10):847-51.

7. Ivanovic Z, Hermitte F, Brunet de la Grange P, Dazey B, Belloc F, Lacombe F, et al. Simultaneous maintenance of human cord blood SCID-repopulating cells and expansion of committed progenitors at low $\mathrm{O} 2$ concentration (3\%). Stem Cells. 2004;22(5):716-24.

8. Hammoud M, Vlaski M, Duchez P, Chevaleyre J, Lafarge X, Boiron JM, et al. Combination of low $\mathrm{O}(2)$ concentration and mesenchymal stromal cells during culture of cord blood CD34(+) cells improves the maintenance and proliferative capacity of hematopoietic stem cells. J Cell Physiol. 2012;227(6): 2750-8.

9. Eliasson $P$, Rehn M, Hammar P, Larsson P, Sirenko O, Flippin LA, et al. Hypoxia mediates low cell-cycle activity and increases the proportion of long-term reconstituting hematopoietic stem cells during in vitro culture. Exp Hematol. 2010;38(4):301-310.e2.

10. Dao MA, Creer MH, Nolta JA, Verfaillie CM. Biology of umbilical cord blood progenitors in bone marrow niches. Blood. 2007;1 10(1):74-81.

11. Suda T, Takubo K, Semenza GL. Metabolic regulation of hematopoietic stem cells in the hypoxic niche. Cell Stem Cell. 2011;9(4):298-310.

12. Mantel CR, O'Leary HA, Chitteti BR, Huang X, Cooper S, Hangoc G, et al. Enhancing hematopoietic stem cell transplantation efficacy by mitigating oxygen shock. Cell. 2015;161(7):1553-65.

13. Lu LL, Liu YJ, Yang SG, Zhao QJ, Wang X, Gong W, et al. Isolation and characterization of human umbilical cord mesenchymal stem cells with hematopoiesis-supportive function and other potentials. Haematologica. 2006;91(8):1017-26.

14. Dahlberg A, Delaney C, Bernstein ID. Ex vivo expansion of human hematopoietic stem and progenitor cells. Blood. 2011;117(23):6083-90.

15. Milazzo L, Vulcano F, Barca A, Macioce G, Paldino E, Rossi S, et al. Cord blood CD34+ cells expanded on Wharton's jelly multipotent mesenchymal stromal cells improve the hematopoietic engraftment in NOD/SCID mice. Eur J Haematol. 2014;93(5):384-91.

16. Gerber HP, Malik AK, Solar GP, Sherman D, Liang XH, Meng G, et al. VEGF regulates haematopoietic stem cell survival by an internal autocrine loop mechanism. Nature. 2002;417(6892):954-8.

17. Larrivée B, Lane DR, Pollet I, Olive PL, Humphries RK, Karsan A. Vascular endothelial growth factor receptor-2 induces survival of hematopoietic progenitor cells. J Biol Chem. 2003;278(24):22006-13.

18. Goodwin RG, Lupton S, Schmierer A, Hjerrild KJ, Jerzy R, Clevenger W, et al. Human interleukin 7: molecular cloning and growth factor activity on human and murine B-lineage cells. Proc Natl Acad Sci U S A. 1989;86(1):302-6.

19. Mohle R, Kanz L. Hematopoietic growth factors for hematopoietic stem cell mobilization and expansion. Semin Hematol. 2007;44(3):193-202.

20. Baldridge MT, King KY, Goodell MA. Inflammatory signals regulate hematopoietic stem cells. Trends Immunol. 2011;32(2):57-65. 
21. Ivanovic Z, Belloc F, Faucher JL, Cipolleschi MG, Praloran V, Dello SP. Hypoxia maintains and interleukin-3 reduces the pre-colony-forming cell potential of dividing CD34(+) murine bone marrow cells. Exp Hematol. 2002;30(1):67-73.

22. Paquet J, Deschepper M, Moya A, Logeart-Avramoglou D, Boisson-Vidal C, Petite $\mathrm{H}$. Oxygen tension regulates human mesenchymal stem cell paracrine functions. Stem Cells Transl Med. 2015;4(7):809-21.

23. Majumdar D, Bhonde R, Datta I. Influence of ischemic microenvironment on human Wharton's Jelly mesenchymal stromal cells. Placenta. 2013;34(8):642-9.

24. Lee SH, Lee YJ, Song CH, Ahn YK, Han HJ. Role of FAK phosphorylation in hypoxia-induced hMSCS migration: involvement of VEGF as well as MAPKS and eNOS pathways. Am J Physiol Cell Physiol. 2010;298(4):C847-56.

25. Xu Y, Malladi P, Chiou M, Bekerman E, Giaccia AJ, Longaker MT. In vitro expansion of adipose-derived adult stromal cells in hypoxia enhances early chondrogenesis. Tissue Eng. 2007:13(12):2981-93.

26. Semenza GL. Hypoxia-inducible factors in physiology and medicine. Cell. 2012;148(3):399-408

27. Ezashi T, Das P, Roberts RM. Low $\mathrm{O} 2$ tensions and the prevention of differentiation of hES cells. Proc Natl Acad Sci U S A. 2005;102(13):4783-8.

28. Mukherjee T, Kim WS, Mandal L, Banerjee U. Interaction between Notch and Hif-alpha in development and survival of Drosophila blood cells. Science. 2011;332:1210-3. https://doi.org/10.1126/science.1199643.

29. Bijlsma MF, Groot AP, Oduro JP, Franken RJ, Schoenmakers SH, Peppelenbosch MP, et al. Hypoxia induces a hedgehog response mediated by HIF-1alpha. J Cell Mol Med. 2009;13(8B):2053-60.

30. Mazumdar J, O'Brien WT, Johnson RS, LaManna JC, Chavez JC, Klein PS, et al. $\mathrm{O}_{2}$ regulates stem cells through Wnt/beta-catenin signalling. Nat Cell Biol. 2010;12(10):1007-13.

31. Liu HL, Liu D, Ding GR, Liao PF, Zhang JW. Hypoxia-inducible factor-1alpha and Wnt/beta-catenin signaling pathways promote the invasion of hypoxic gastric cancer cells. Mol Med Rep. 2015;12(3):3365-73.

Ready to submit your research? Choose BMC and benefit from:

- fast, convenient online submission

- thorough peer review by experienced researchers in your field

- rapid publication on acceptance

- support for research data, including large and complex data types

- gold Open Access which fosters wider collaboration and increased citations

- maximum visibility for your research: over $100 \mathrm{M}$ website views per year

At BMC, research is always in progress.

Learn more biomedcentral.com/submissions 